Check for updates

Cite this: RSC Adv., 2018, 8, 19362

Received 6th February 2018

Accepted 18th May 2018

DOI: 10.1039/c8ra01146j

rsc.li/rsc-advances

\title{
Dispersing upconversion nanocrystals in PMMA microfiber: a novel methodology for temperature sensing
}

\author{
Muhammad Khuram Shahzad, (D) a Yundong Zhang, (D) *a Lugui Cui, (D) ${ }^{\mathrm{b}}$ Lu Liu, (D) ${ }^{\mathrm{b}}$ \\ Mehwish Khalid Butt iD ${ }^{b}$ and Hanyang Li iD *b
}

\begin{abstract}
This paper reports the synthesis of a $\beta-\mathrm{NaYF}_{4}: \mathrm{Yb}^{3+} / \mathrm{Tm}^{3+}$ phosphor by a thermal decomposition method and focuses on the fabrication of microfibers by the co-doping of nanocrystals with PMMA solution via a facile drawing method. The structural characteristics of the nanocrystals are studied by XRD and TEM techniques. Meanwhile, the optical properties of the microfibers are probed by wave guiding performance and upconversion spectroscopy. With the excitation of a $980 \mathrm{~nm}$ laser source, the microfiber presented blue upconversion emission of $\mathrm{Tm}^{3+}$ ions. The fluorescence intensity ratio (FIR) method is utilized for the non-thermally coupling transition $\left({ }^{1} \mathrm{D}_{2} \rightarrow{ }^{3} \mathrm{~F}_{4}\right.$ (452 nm) and ${ }^{1} \mathrm{G}_{4} \rightarrow{ }^{3} \mathrm{H}_{6}$ (476 $\mathrm{nm})$ ) levels to carry out the optical thermometry. The maximum sensitivity is recorded at $298 \mathrm{~K}$ and is $0.00157 \mathrm{~K}^{-1}$. The results suggest that the microfibers have potential applications in thermometry with high sensitivity.
\end{abstract}

\section{Introduction}

The majority of luminescent materials emit light at longer wavelengths compared to the excitation source. There are many technological applications that can benefit from atypical materials that convert lower energy photons into higher energy photons, by a process known as upconversion (UC). Upconversion can be achieved through a variety of optical process, such as two photon absorption, second-harmonic generation, two step absorption and energy transfer upconversion at low excitation intensity, and has been the subject of research interest over the last decade. Moreover, upconversion materials doped with rare earth ions have been used extensively because of their attractive applications such as lighting, ${ }^{1}$ multiple color displays, ${ }^{2}$ sensors ${ }^{3}$ and biological ${ }^{4}$ and optical thermal sensitivity. ${ }^{5-13}$ Dye doped PMMA (polymethyl methacrylate) nanowire fluorescence guiding has been applied to a series of integrated microstructural optical devices in one dimension, including nano-lasers, micro-optical sensors and fiber biosensors. ${ }^{14-18}$ Due to their high efficiency, fluorescence photons can be coupled into guided modes of microfibers. ${ }^{19}$ Furthermore, upconversion materials such as oxyfluoride glass-ceramics, $\mathrm{Ca}\left(\mathrm{WO}_{4}\right)_{3}$ and $\beta-\mathrm{NaLuF}_{4}$, after co-doping with rare earth ions, were used for temperature sensing and the fabrication of

${ }^{a}$ National Key Laboratory of Tunable Laser Technology, Institute of Opto-Electronics, Department of Electronics Science and Technology, Harbin Institute of Technology (HIT), Harbin 150080, China. E-mail: ydzhang@hit.edu.cn

${ }^{b}$ Key Lab of In-fiber Integrated Optics, Ministry Education of China, Harbin Engineering University, Harbin 150080, China. E-mail: hanyang_li@qq.com nanowires and microtubes. ${ }^{20-24}$ Generally, such techniques are expensive and the fabrication process is difficult. The fabrication process for nanowires and microtubes from glass-ceramics and crystals are not simple and they have a high cost, and thus their applications are highly limited. Fortunately, this disadvantage may be countered by the co-doping of nanocrystals with a polymer for the fabrication of microfibers. Therefore, it is promising to investigate whether upconversion nanocrystal polymer microfiber (UCNPMF) can be used in an easier and cheaper way. It is noteworthy that $\mathrm{Tm}^{3+}$ and $\mathrm{Yb}^{3+}$ ions possess relatively high luminescent efficiency. These ions exhibit visible upconversion luminescence pumped by the near infrared (NIR) region and therefore the doping of nanocrystals with $\mathrm{Tm}^{3+} / \mathrm{Yb}^{3+}$ is commonly used for the investigation of optical properties, but co-doping with a polymer is of growing interest for the fabrication of microfibers. Before now a few investigations for optical sensing have been reported, mainly concerning the fabrication of upconversion microfibers in a simplistic way, therefore it is important and novel to focus on a simple strategy for fabrication of microfibers and the use of a single microfiber for temperature sensing.

Herein, we have used a thermal decomposition technique for the synthesis of $\beta-\mathrm{NaYF}_{4}: \mathrm{Yb}^{3+} / \mathrm{Tm}^{3+}$ ions, while microfibers are successfully fabricated by the co-doping of nanocrystals with PMMA solution by applying a facile drawing method. Under the excitation of a $980 \mathrm{~nm}$ fiber laser the microfibers demonstrated light transmission and blue upconversion luminescence. The wave guiding and upconversion luminescent properties of the microfibers will be discussed systemically. Subsequently, the light transmission loss coefficients and coupling efficiency of 
two microfibers with different angles were evaluated. The fluorescence intensity ratio (FIR) method is used between the ${ }^{1} \mathrm{D}_{2}$ $\rightarrow{ }^{3} \mathrm{~F}_{4}(452 \mathrm{~nm})$ and ${ }^{1} \mathrm{G}_{4} \rightarrow{ }^{3} \mathrm{H}_{6}(476 \mathrm{~nm})$ emissions. Afterwards, the sensitivity is calculated in the temperature range from $298 \mathrm{~K}$ to $338 \mathrm{~K}$. The results are evidence that the microfiber can be used as an excellent candidate for optical temperature sensing.

\section{Materials \& methods}

\subsection{Synthesis of $\beta-\mathrm{NaYF}_{4}: \mathrm{Yb}^{3+} / \mathrm{Tm}^{3+}$ nanoparticles}

All of the chemicals are analytical grade reagents and are used without further purification. The $\beta-\mathrm{NaYF}_{4}$ doped with $\mathrm{Yb}^{3+} /$ $\mathrm{Tm}^{3+}$ powder was prepared using a thermal decomposition method..$^{25} \mathrm{In}$ a typical process, $2 \mathrm{ml}$ of a methanol solution of $\mathrm{LnCl}_{3}(\mathrm{Ln}=\mathrm{Tm}, \mathrm{Yb}$ and $\mathrm{Y}$, total amount of $1 \mathrm{mmol}$, with a ratio of $79.5: 20: 0.5)$ was magnetically mixed with oleic acid (OA) $(19 \mathrm{mmol})$ and octadecene (ODE) $(46 \mathrm{mmol})$ in a $100 \mathrm{ml}$ threenecked flask. Before cooling to room temperature, the mixture was degassed under an argon (Ar) flow and then heated up to $150{ }^{\circ} \mathrm{C}$ for $30 \mathrm{~min}$ to form a clear solution. $12 \mathrm{ml}$ of a methanol solution containing $\mathrm{NH}_{4} \mathrm{~F}(4 \mathrm{mmol})$ and $\mathrm{NaOH}(2.5 \mathrm{mmol})$ was added to the solution of $\mathrm{LnCl}_{3}$ in $\mathrm{OA}$ and $\mathrm{ODE}$ and stirred for $60 \mathrm{~min}$. The mixture was slowly heated to remove the methanol and any residual water. The mixture was then quickly heated to the reaction temperature of $300{ }^{\circ} \mathrm{C}$ and aged for 2 hours. The solution was cooled down to room temperature and was washed with cyclohexane, ethanol and methanol at least 4 times before the final $\mathrm{NaYF}_{4}$ nanocrystals were re-dispersed in $10 \mathrm{ml}$ cyclohexane in preparation for their use.

\subsection{Fabrication of the microfibers}

In order to fabricate the microfibers, firstly, a block of PMMA was dissolved in chloroform and the nanocrystals were dispersed in cyclohexane. The two kinds (nanocrystal and PMMA) of solution were mixed, followed by ultra-sonicating for one hour to get a uniform solution. The weight ratio of PMMA to nanocrystal was about $200: 1$. A fiber probe with a tip (diameter $\sim 10 \mu \mathrm{m}$ ) was fabricated using a flame heated drawing process using the single mode fiber with diameter of $125 \mu \mathrm{m}$. The fiber tip was fixed with a plate and connected to a direct current (DC) motor. When the fiber tip was immersed into the mixed solution (nanocrystal and PMMA) the DC motor was used to pull out the fiber tip for the fabrication of microfibers with different diameter. We controlled the speed of pull and uniform diameter of the microfibers using the DC motor. The drawing process is shown in Fig. 1(a-c). Lastly, a double fiber tip was used for cutting the microfibers into small pieces. The diameter of a microfiber can be increased or decreased by changing the speed of the DC motor. The fiber probe tip was fixed on a three dimensional (3D) adjustment stage to contact the microfiber which was further used to investigate the optical properties.

\subsection{Optical characterization}

The characterization and optical properties of UCNPMF were studied under optical microscopy. Fig. 2 shows the experimental set up. The fiber probe tip was fixed on the 3D adjustment stand which was coupled to a $980 \mathrm{~nm}$ laser source for the excitation of a microfiber. A heater was used to increase the temperature of the sample. Thus, photoluminescence (PL) signals were collected using $10 \times$ (numerical aperture $(\mathrm{NA})=$ $0.25), 20 \times(\mathrm{NA}=0.4)$ and $40 \times(\mathrm{NA}=0.65)$ objectives. The emission spectra were observed using a $40 \times(\mathrm{NA}=0.65)$ objective. Moreover, a $980 \mathrm{~nm}$ filter was used to overcome the reflection of the fiber laser. The beam splitter was applied for splitting the emission spectra of the microfiber to the spectrometer (Ocean optics QE Pro) and the charge-coupled device (CCD) camera (Olympus DP 26).

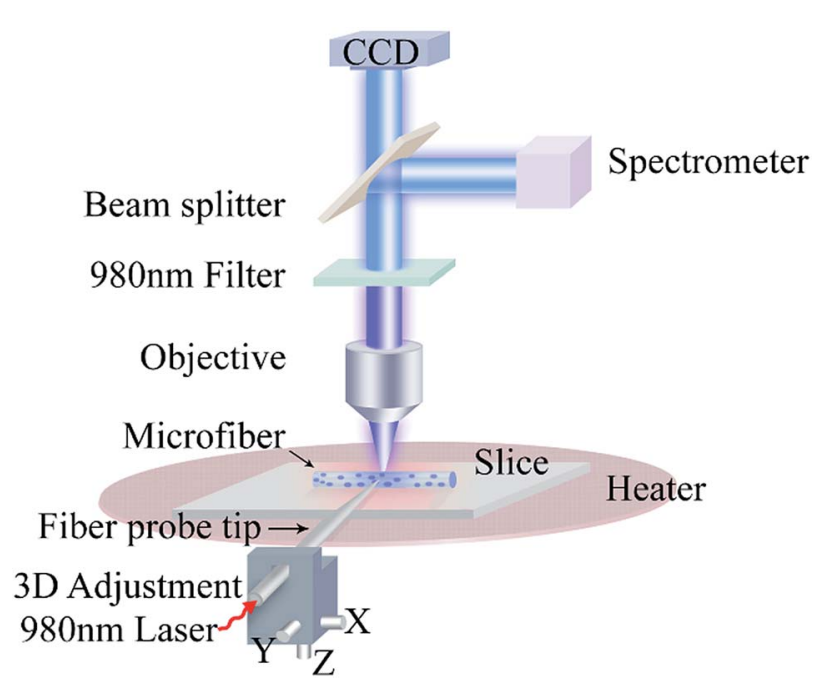

Fig. 2 Schematic diagram for optical characterization. (a)

(b)

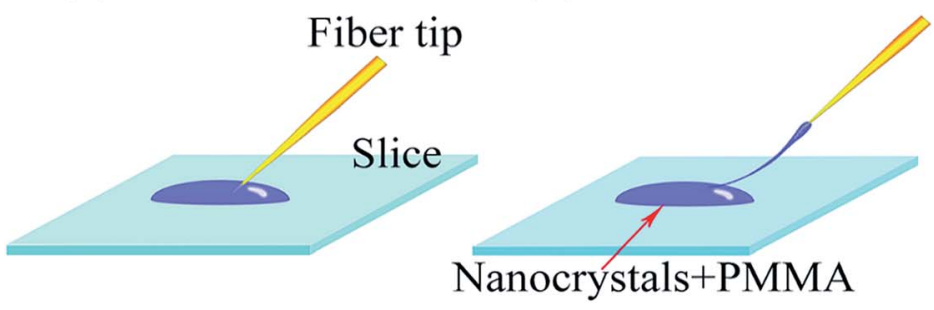

(c)

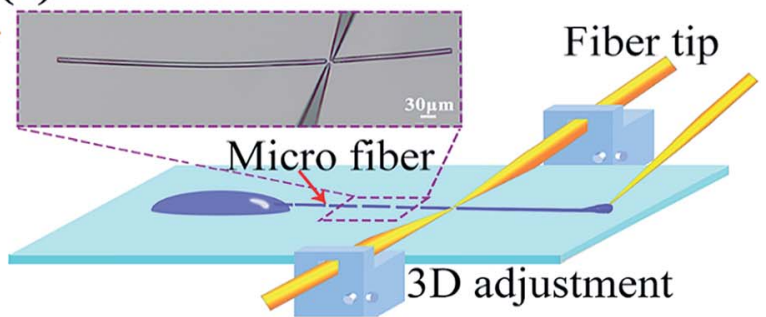

Fig. 1 (a-c) Fabrication of microfibers from incorporated solutions of PMMA and nanocrystals by a facile drawing process. 


\section{Results and discussions}

The crystal structure was characterized using XRD analysis. Fig. 3(a) shows that the pattern is consistent with standard values of hexagonal phase $\mathrm{NaYF}_{4}$. It can be clearly seen that the relative intensity and position of all diffraction peaks have closely matched with standard peaks (JCPDS no. 28-1152). The well-defined and sharp diffraction peaks suggest that synthesized nanoparticles are well crystallized and no raw materials were detected in an as-synthesized sample confirming that the $\mathrm{Tm}^{3+}$ and $\mathrm{Yb}^{3+}$ are well doped into $\beta-\mathrm{NaYF}_{4}$ lattices. Fig. 3 (b and c) show typical transmission electron microscopy (TEM) images of nanocrystals which indicate the uniform particles distributed monodispersely, with an average diameter of $\sim 23 \mathrm{~nm}$. Fig. 4(a and b) show the SEM images of a microfiber with a diameter of $\sim 2 \mu \mathrm{m}$. One can clearly see the smooth surfaces of the microfibers. On closer inspection, the inset figures indicate that the microfibers are well-defined and homogeneous.

We co-doped $\beta-\mathrm{NaYF}_{4}: \mathrm{Yb}^{3+} / \mathrm{Tm}^{3+}$ with PMMA solution to fabricate the microfibers. In order to prove that $\beta-\mathrm{NaYF}_{4}: \mathrm{Yb}^{3+}$ / $\mathrm{Tm}^{3+}$ are present in a single microfiber, a small diameter microfiber was prepared and characterized via TEM. Fig. 4(c) shows the TEM images of a single microfiber, indicating that $\beta-\mathrm{NaYF}_{4}: \mathrm{Yb}^{3+} / \mathrm{Tm}^{3+}$ is well-dispersed in a single microfiber.

In order to probe the optical properties of an individual microfiber a $980 \mathrm{~nm}$ laser source was used to illuminate the microfiber at the middle and top points. Fig. 5(a) shows the microfiber (diameter $\sim 11 \mu \mathrm{m}$ and length $\sim 405 \mu \mathrm{m}$ ) which was excited at the middle point with a white and dark background under a $10 \times$ objective. The two bright end points act as an optical waveguide and suggest that the microfiber absorbs the light and propagates towards the end spots uniformly. ${ }^{26}$ Fig. 5 (b) shows the true-color PL image of a microfiber under a dark background. The PL microscope image was obtained with a $10 \times$ objective. Then, part of the microfiber was magnified using a $20 \times$ objective and further magnified using a $40 \times$ objective. The brightness proved that the distribution of nanocrystals within the microfiber is uniform on this large diameter scale. There is no evidence of appreciable scattering centers such as break points or UCNPMF clustering. Furthermore, to analyze the wave guiding performance, Fig. 5(c) shows the propagation of light with different excited points of a microfiber under a dark background (diameter $\sim 6 \mu \mathrm{m}$ ) under a $980 \mathrm{~nm}$ fiber laser. The microfiber was excited at different positions to measure the normalized PL intensity of output spots but the brightness intensity remained the same along the excited point positions.

We used Adobe Photoshop to convert the output spot images from RGB (red, green and blue) to gray styles. The gray styles values were calculated using Matlab for characterizing the corresponding intensities, as used in previous work. ${ }^{27}$ The normalization was considered in measured intensities at the end faces against those measured at each excited location on the microfiber due to little fluctuation in excited power. It is observed that self-absorption and Rayleigh scattering hinder
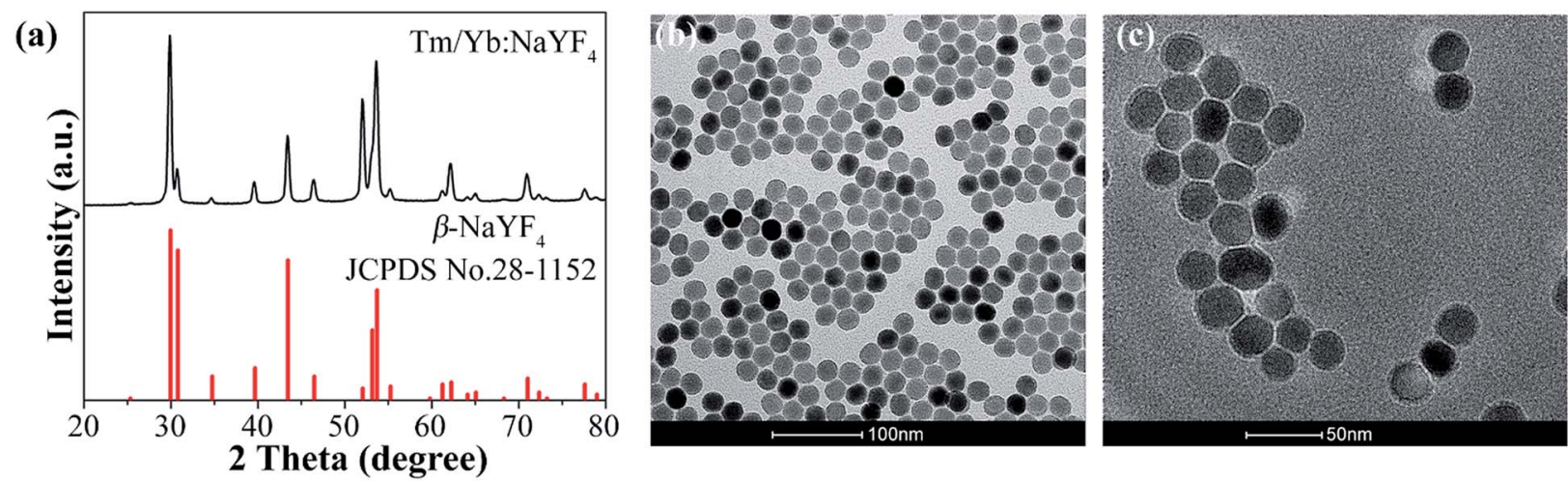

Fig. 3 The characterization of the nanocrystals. (a) XRD pattern of $\beta-\mathrm{NaYF}_{4}: 20 \% \mathrm{Yb}^{3+}, 5 \% \mathrm{Tm}^{3+}$ and (b and c) transmission electron microscopy (TEM) images of $\beta-\mathrm{NaYF}_{4}: 20 \% \mathrm{Yb}^{3+} / 5 \% \mathrm{Tm}^{3+}$ at $100 \mathrm{~nm}$ and $50 \mathrm{~nm}$ scales.
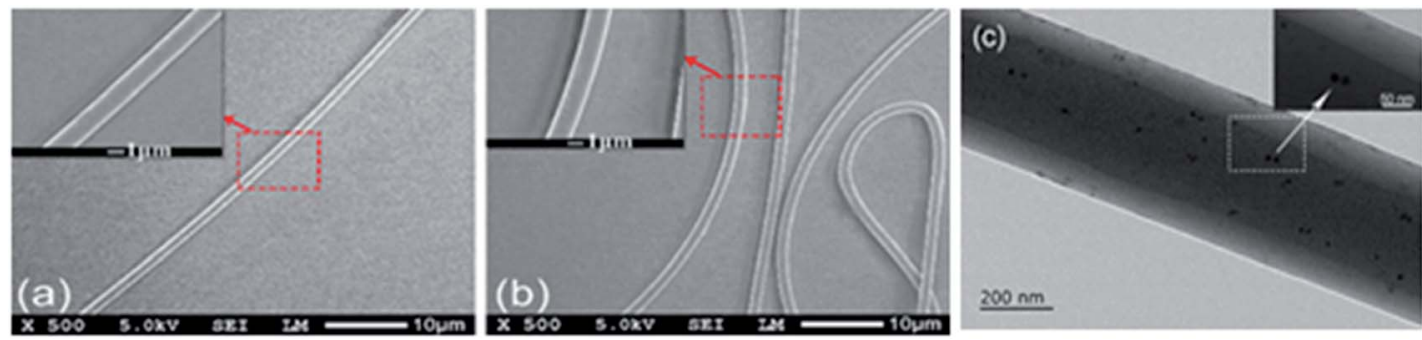

Fig. 4 ( $a$ and b) The scanning electron microscopy (SEM) images of microfibers with diameter $\sim 2 \mu \mathrm{m}$. (c) The transmission electron microscopy (TEM) image of a microfiber with a small diameter. 

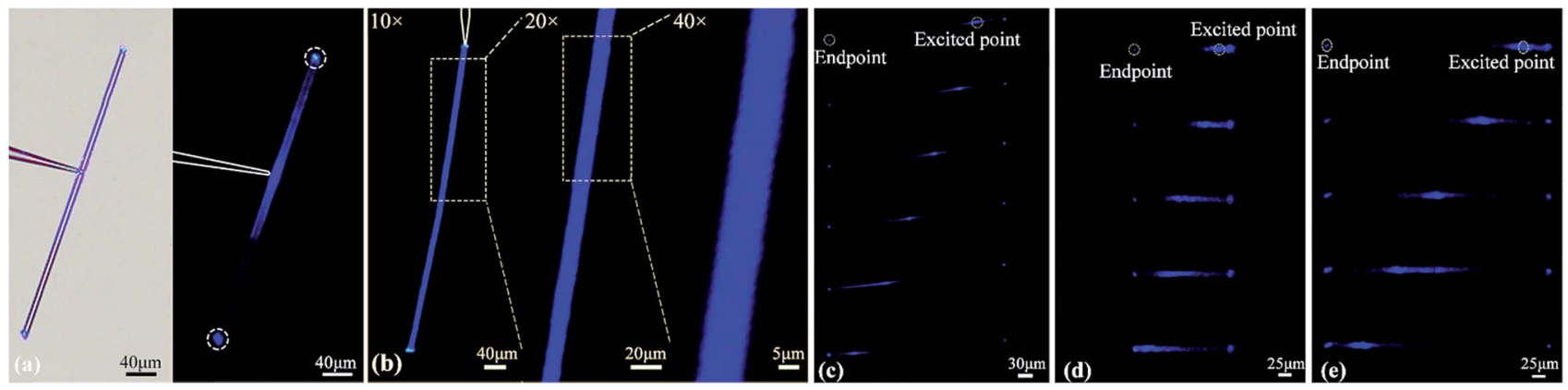

Fig. 5 Wave guiding performance of upconversion UCNPMF. (a) The photoluminous (PL) blue color image of a microfiber with a diameter of 11 $\mu \mathrm{m}$ and a length of $405 \mu \mathrm{m}$; (b) the PL image of microfiber (diameter of $12 \mu \mathrm{m}$ and length of $571 \mu \mathrm{m}$ ) with $10 \times, 20 \times$ and $40 \times$ objectives; (c-e) PL images of three microfibers with black background (diameters $\sim 6 \mu \mathrm{m}, \sim 10 \mu \mathrm{m}$ and $\sim 13 \mu \mathrm{m}$ ) at different excited point positions.

the propagation of light in microfibers and become asource of optical loss. Similarly, Fig. 5(d and e) show that the propagation of light in microfibers (diameter $\sim 10$ and $13 \mu \mathrm{m}$ ) with different excited points under a dark background and follows the same phenomena as in Fig. 5(c). Moreover, Fig. 6(a-c) illustrates the relationship between guide distance and PL intensity, with inset dark images of the microfibers (diameter $\sim 6 \mu \mathrm{m}, \sim 10 \mu \mathrm{m}$ and $\sim 13 \mu \mathrm{m}$, respectively). The experimental data was fitted using a first order exponential decay curve with reference to the Lambert-Beer law which is given as follows.

$$
I_{\text {endpoint }} / I_{0}=\exp (-\alpha d)
$$

where $I_{\text {endpoint }}$ is the intensity of the endpoint of the microfiber and $I_{0}$ is the intensity of the excited spot, $d$ is the propagation distance and $\alpha$ is the fitting parameter. The corresponding curves in Fig. 6(a-c) show that by increasing the propagation distance the PL intensity of the output spots decreases exponentially. Thus, the transmission loss coefficients $(\alpha)$ of different microfibers with diameters $\sim 6 \mu \mathrm{m}, \sim 10 \mu \mathrm{m}$ and $\sim 13 \mu \mathrm{m}$ are $\sim 135.263 \mathrm{~cm}^{-1}, 160.88 \mathrm{~cm}^{-1}$ and $261.98 \mathrm{~cm}^{-1}$, respectively.

From Fig. 6(a-c), it is also observed that when diameter of the microfiber increases the transmission loss in a microfiber also increases. In fact, the transmitted light in a microfiber is adversely affected by its increasing diameter and becomes the source of more propagation loss due to self-absorption of wave guided PL. ${ }^{28}$ The lanthanide $\left(\mathrm{Ln}^{3+}\right)$ ions have a great absorption cross-section area, it therefore largely overlaps with the emission cross-section that undergoes a serious fluorescence self-absorption. ${ }^{29}$ If the dimension of a microfiber is less than wavelength, it leads to Rayleigh scattering which agreed with CdSe/ZnS-doped nanofibers. ${ }^{30}$ These results suggest that the wave guiding performance of the microfibers $\left(\beta-\mathrm{NaYF}_{4}: \mathrm{Yb}^{3+} /\right.$ $\mathrm{Tm}^{3+}$ co-doped with PMMA) are closely matched with the wave guiding performance of microtubes ${ }^{31}$ and demonstrate the typical active and passive wave guide features of nanowires. ${ }^{32,33}$

In order to explore the coupling efficiency of two microfibers we studied the image brightness and normalized PL intensity of emitted light. Fig. 7(a-f) show the coupling efficiency of two microfibers with different angles between them. A microfiber with a diameter of $10 \mu \mathrm{m}$ was excited using a $980 \mathrm{~nm}$ laser fiber tip. Another microfiber with a diameter of $13 \mu \mathrm{m}$ is placed underneath. The position of the excited spot remained same but the angle between the two microfibers was changed. Fig. 7 (a) shows that when the cross angle is $106^{\circ}$ between two microfibers then the coupling efficiency becomes very low. We estimated the coupling efficiency by studying the image brightness and normalized PL intensity of the emission light. Here, we defined coupling efficiency as $\eta=I_{\text {output }} / I_{\text {excited point }}$ and the estimated efficiency is about $1.8 \%$. Similarly, Fig. $7(\mathrm{~b}-\mathrm{f})$ show that when the cross angle is tuned to $83^{\circ}, 59^{\circ}, 44^{\circ}, 16^{\circ}$ and $5^{\circ}$, the estimated efficiency is about $2.5 \%, 5 \%, 11.6 \%, 16.5 \%$ and $22.27 \%$ respectively. It can be seen that the brightness of the end points gradually increases after decreasing the cross angle between two microfibers. However, the brightness of the end points shows an obvious decrease while increasing the
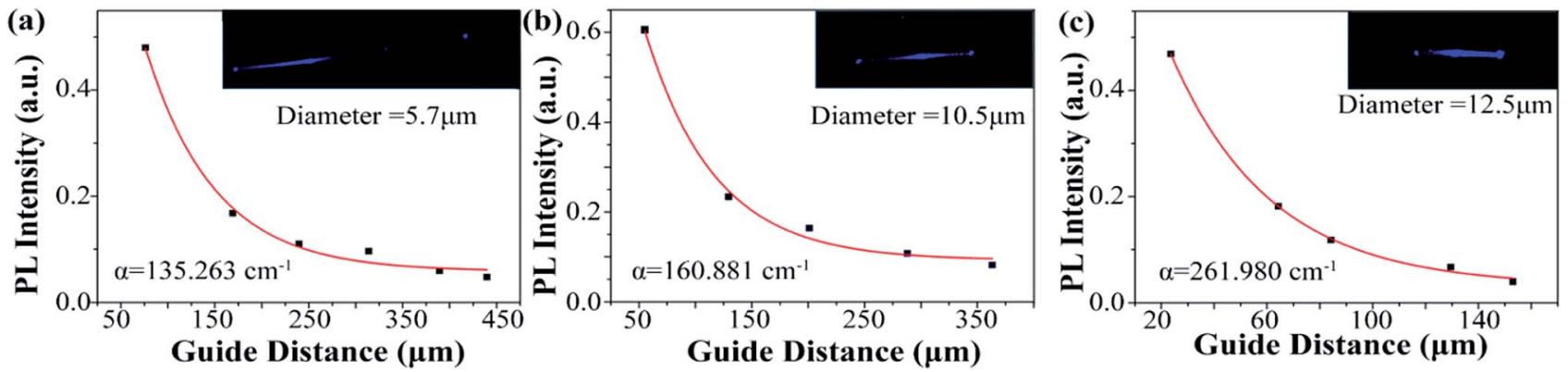

Fig. 6 (a-c) The relationship between PL intensity and guided distance of microfibers at diameters of $\sim 6 \mu \mathrm{m}, \sim 11 \mu \mathrm{m}$ and $\sim 13 \mu \mathrm{m}$, respectively. 

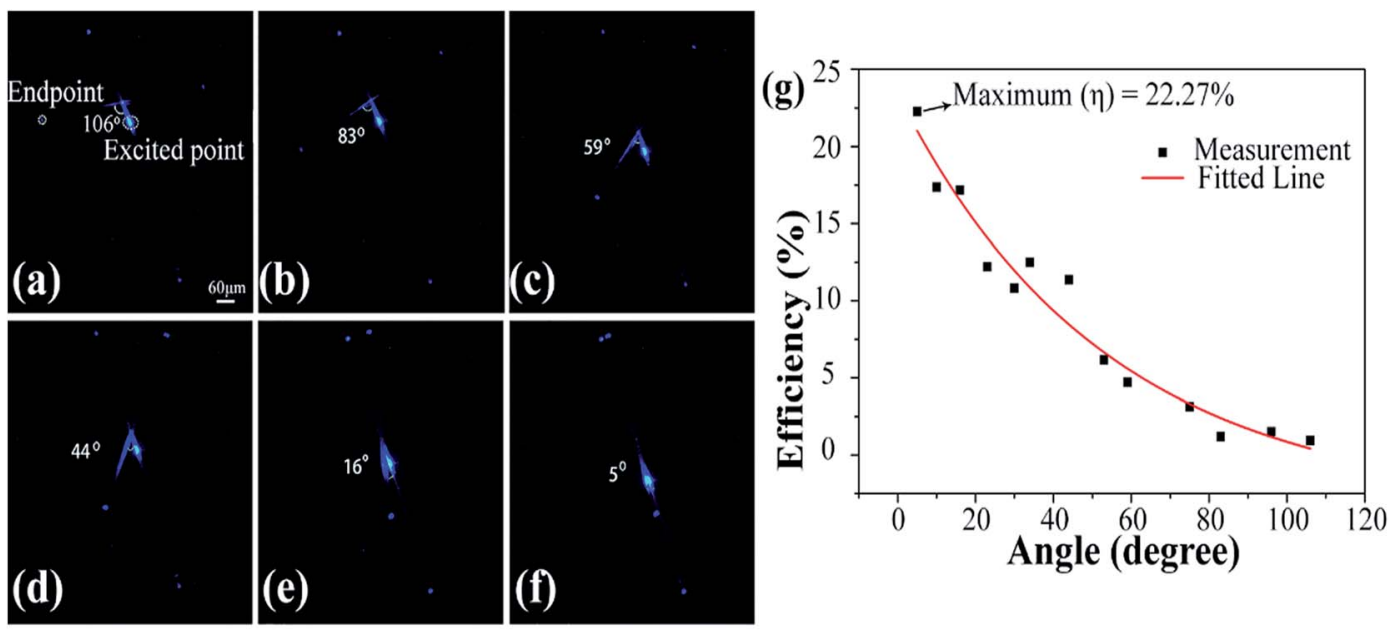

Fig. 7 (a-f) True-color PL microscope images of two microfibers with different cross angles (diameter $\sim 10 \mu \mathrm{m}$ and $\sim 13 \mu \mathrm{m}$ ) under excitation of a $980 \mathrm{~nm}$ fiber laser. (g) The relationship between coupling efficiency and angles between two microfibers.

angle between them. We found that tuning the cross angle between two microfibers could make the coupling more prominent. It is interesting to find that the brightness of the end points exhibits significantly angle-dependent behavior with respect to two microfibers. Fig. $7(\mathrm{~g})$ shows the relationship between efficiency (\%) and angle (degree). The experimental data can be fitted using a first order decay function. The maximum coupling efficiency at $5^{\circ}$ is recorded as $22.27 \%$. Thus, the increasing angle is attributed to decreasing the coupling efficiency. The coupling efficiency depends on an angle between two microfibers. Hence, these results correlate with wavelengthconverted wave guiding in dye-doped polymer nanofibers. ${ }^{34}$

Fig. 8(a) represents the luminescence decay profile of $\beta$ $\mathrm{NaYF}_{4}: \mathrm{Yb}^{3+} / \mathrm{Tm}^{3+}$. The life time decay curves at $476 \mathrm{~nm}\left({ }^{1} \mathrm{G}_{4} \rightarrow\right.$ $\left.{ }^{3} \mathrm{H}_{6}\right)$ and $452 \mathrm{~nm}\left({ }^{1} \mathrm{D}_{2} \rightarrow{ }^{3} \mathrm{~F}_{4}\right)$ distinguish the upconversion mechanisms. Moreover, Fig. 8(b) shows the energy level diagram of $\mathrm{Tm}^{3+}$ and $\mathrm{Yb}^{3+}$ ions. The incident pump photons of the $980 \mathrm{~nm}$ laser source mainly excite $\mathrm{Yb}^{3+}$ ions from the ${ }^{2} \mathrm{~F}_{7 / 2}$ to ${ }^{2} \mathrm{~F}_{5 / 2}$ levels. The three successive energy transfers (ETs) from $\mathrm{Yb}^{3+}$ to $\mathrm{Tm}^{3+}$ populate the ${ }^{3} \mathrm{H}_{5},{ }^{3} \mathrm{~F}_{2,3}$ and ${ }^{1} \mathrm{G}_{4}$ levels of $\mathrm{Tm}^{3+} .{ }^{35}$ The $\mathrm{Tm}^{3+}-\mathrm{Tm}^{3+}$ interaction is weak in the sample with a low $\mathrm{Tm}^{3+}$ concentration owing to the large energy mismatch $\left(\sim 3516 \mathrm{~cm}^{-1}\right)$ in the transfer process ${ }^{2} \mathrm{~F}_{5 / 2} \rightarrow{ }^{2} \mathrm{~F}_{7 / 2}\left(\mathrm{Yb}^{3+}\right): \mathrm{G}_{4} \rightarrow{ }^{1} \mathrm{D}_{2}\left(\mathrm{Tm}^{3+}\right)$.

${ }^{3} \mathrm{~F}_{2} \rightarrow{ }^{3} \mathrm{H}_{6}\left(\mathrm{Tm}^{3+}\right):{ }^{3} \mathrm{H}_{4} \rightarrow{ }^{1} \mathrm{D}_{2}\left(\mathrm{Tm}^{3+}\right)$ may alternatively play the most important role in populating ${ }^{1} \mathrm{D}_{2} \cdot{ }^{36,37}$ As a result, the ${ }^{1} \mathrm{D}_{2},{ }^{1} \mathrm{G}_{4},{ }^{3} \mathrm{~F}_{2}$ and ${ }^{3} \mathrm{H}_{4}$ levels are populated and five emission peaks at $452 \mathrm{~nm}, 476 \mathrm{~nm}, 647 \mathrm{~nm}, 697 \mathrm{~nm}$, and $810 \mathrm{~nm}$ originate from the ${ }^{1} \mathrm{D}_{2} \rightarrow{ }^{3} \mathrm{~F}_{4}(452 \mathrm{~nm}),{ }^{1} \mathrm{G}_{4} \rightarrow{ }^{3} \mathrm{H}_{6}(476 \mathrm{~nm}),{ }^{1} \mathrm{G}_{4} \rightarrow$ ${ }^{3} \mathrm{~F}_{4}(647 \mathrm{~nm}),{ }^{3} \mathrm{~F}_{2} \rightarrow{ }^{3} \mathrm{H}_{6}(697 \mathrm{~nm})$, and ${ }^{3} \mathrm{H}_{4} \rightarrow{ }^{3} \mathrm{H}_{6}(810 \mathrm{~nm})$ transitions of $\mathrm{Tm}^{3+}$ ions, respectively. Thus, the population of states ${ }^{1} \mathrm{D}_{2}$ and ${ }^{1} \mathrm{G}_{4}$ come from four-photon and three-photon upconversion processes which confirms that ET: ${ }^{3} \mathrm{~F}_{2} \rightarrow{ }^{3} \mathrm{H}_{6}$ $\left(\mathrm{Tm}^{3+}\right):{ }^{3} \mathrm{H}_{4} \rightarrow{ }^{1} \mathrm{D}_{2}\left(\mathrm{Tm}^{3+}\right.$ ) (four-photon upconversion process) is the fundamental process in populating the ${ }^{1} \mathrm{D}_{2}$ state.

To investigate the optical-thermal characteristics of UCNPMF, Fig. 9(a) demonstrates the emission spectra in the range from 400 to $800 \mathrm{~nm}$ and upconversion spectra were measured in the temperature range from $298 \mathrm{~K}$ to $338 \mathrm{~K}$ (acquired after $5{ }^{\circ} \mathrm{C}$ ). We used $0.64 \mathrm{~mW}$ laser pumping power to avoid the thermal effect. We observed that, as a result of (a)

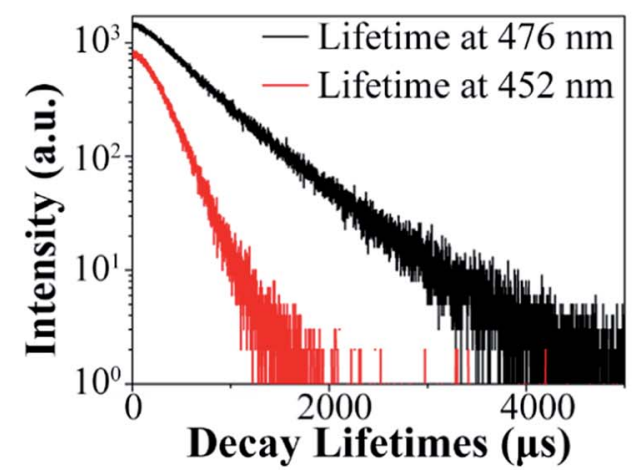

(b)

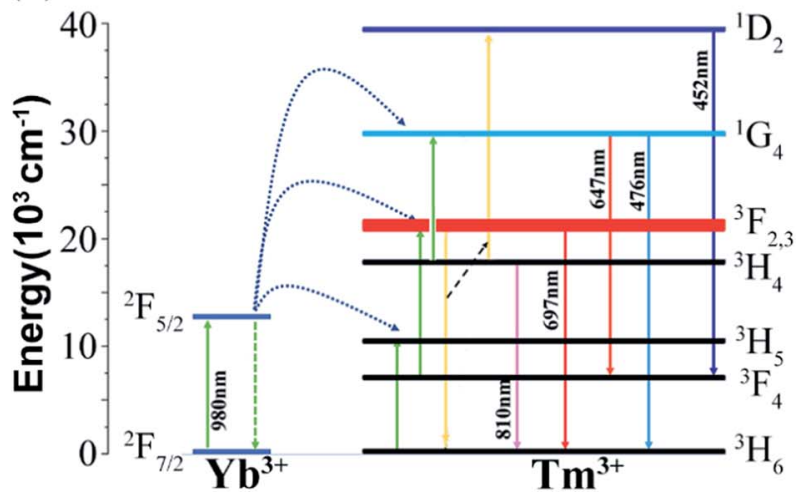

Fig. 8 (a) Decay curves for ${ }^{1} \mathrm{D}_{2} \rightarrow{ }^{3} \mathrm{~F}_{4}(452 \mathrm{~nm})$ and ${ }^{1} \mathrm{G}_{4} \rightarrow{ }^{3} \mathrm{H}_{6}(476 \mathrm{~nm})$ emission of UCNPMF excited at $980 \mathrm{~nm}$. (b) Energy diagram of Yb ${ }^{3+}$ and $\mathrm{Tm}^{3+}$ with the possible upconversion mechanism under $980 \mathrm{~nm}$ excitation. 
(a)

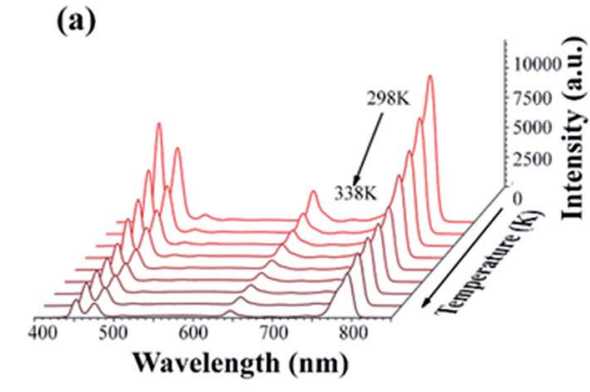

(b)

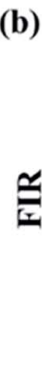

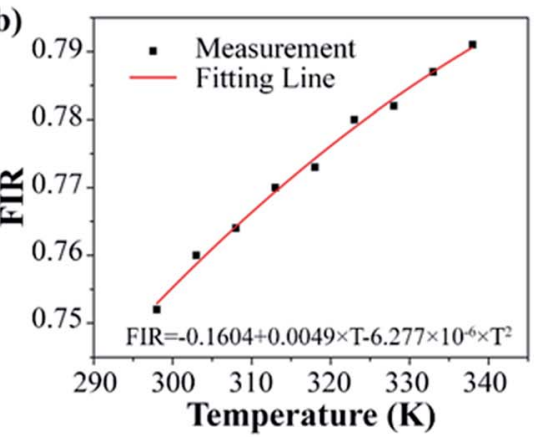

(c)

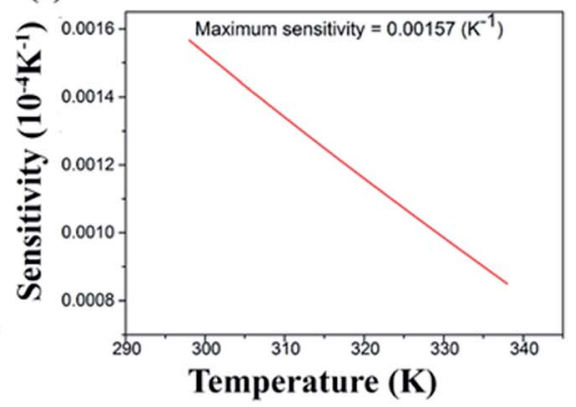

Fig. 9 Optical characteristic of upconversion nanocrystal polymer microfiber (UCNPMF). (a) Emission spectra of UCNPMF calculated in the temperature region from 298 to $338 \mathrm{~K}$ under a range from 400 to $850 \mathrm{~nm}$. (b) The relationship between FIR and temperature for UCNPMF. (c) The relative sensitivity of a microfiber under the excitation of a $980 \mathrm{~nm}$ fiber laser with different temperatures ranging from 298 to $338 \mathrm{~K}$.

Table 1 Comparison of sensitivity and temperature sensing region of $\mathrm{Tm}^{3+}$ in different host materials

\begin{tabular}{llll}
\hline Phosphor & Maximum sensitivity $\left(\mathrm{K}^{-1}\right)$ & Temperature range (K) & References \\
\hline $\mathrm{Tm}^{3+}\left(\mathrm{NaYF}_{4}\right)$ & 0.00157 & $298-338$ & This work \\
$\mathrm{Tm}^{3+}\left(\mathrm{NaLuF}_{4}\right)$ & 0.00045 & $250-600$ & 44 \\
$\mathrm{Tm}^{3+}\left(\mathrm{Ca}\left(\mathrm{WO}_{4}\right)_{3}\right)$ & 0.00057 & $313-573$ & 45 \\
$\mathrm{Tm}^{3+}($ oxyfluoride glass ceramic $)$ & 0.00030 & $297-703$ & 46 \\
$\mathrm{Tm}^{3+}(\text { oxyfluoride glass ceramic })_{\mathrm{Tm}^{3+}\left(\mathrm{NaNbO}_{3}\right)}$ & 0.00042 & $303-623$ & 47 \\
$\mathrm{Yb}^{3+} / \mathrm{Tm}^{3+}: \mathrm{CaF}_{2}$ & 0.00080 & $293-353$ & 48 \\
& 0.0025 & $298-323$ & 49
\end{tabular}

increased temperature, the emission intensities decrease and vice versa. To confirm that different decay rates are caused by temperature changes, the microfiber was emitted until the temperature reduced from 338 to $298 \mathrm{~K}$. It was found that the emission intensity was back to the original location in spectrum. In fact, the upconversion nanocrystal (UCNC) powder pumped using a $980 \mathrm{~nm}$ laser source in temperature ranges from $100 \mathrm{~K}$ to $700 \mathrm{~K}$ could make an effective optical thermometer. ${ }^{38}$ In this paper, the FIR technique was applied to examine the optical temperature sensing of UCNPMF. The energy gap between the ${ }^{1} \mathrm{D}_{2}$ and ${ }^{1} \mathrm{G}_{4}$ levels $\left(\Delta E_{\mathrm{DG}} \sim 6476 \mathrm{~cm}^{-1}\right)$ does not exist between $200-2000 \mathrm{~cm}^{-1}$ and therefore, the FIR originated from non-thermally coupled levels $\left({ }^{1} \mathrm{G}_{4} \rightarrow{ }^{3} \mathrm{H}_{6}(476 \mathrm{~nm})\right.$ and ${ }^{1} \mathrm{D}_{2}$ $\left.\rightarrow{ }^{3} \mathrm{~F}_{4}(452 \mathrm{~nm})\right)$ of $\mathrm{Tm}^{3+}$ transitions. ${ }^{39,40}$ As can be seen in Fig. 9(b), the FIR increases monotonically with the increase in temperature. The fitted curve shows the increase in temperature. The fitted curve shows the relationship between FIR and temperature (K). The experimental data as a function of the temperature can be fitted using a polynomial function:

$$
\mathrm{FIR}=\frac{I_{476}}{I_{452}}=C_{1}+B_{1} T+B_{2} T^{2}
$$

where $C_{1}, B_{1}$ and $B_{2}$ are constants, $I_{476}$ is the intensity of the lower level, $I_{452}$ is the intensity of upper level and $T$ is the absolute temperature. The constant values are derived from fitting the curve which is given in Fig. 9(b).

The relative sensitivity is a paramount parameter for sensing applications. It is denoted by $S_{\mathrm{r}},{ }^{41-43}$ which has been calculated using eqn (3).

$$
S_{\mathrm{r}}=\frac{\mathrm{d}(R)}{R \mathrm{~d} t}=\left(0.0049-12.54 \times 10^{-6} \times T\right) / R
$$

where FIR $=R=$ fluorescence intensity ratio of $\mathrm{Tm}^{3+}$.

In order to better understand the temperature sensing performance, the relative sensitivity was calculated using eqn (3) and also plotted in Fig. 9c in the temperature range of 298$338 \mathrm{~K}$. It is clearly seen that the relative sensitivity gradually decreases with the rise in temperature and the maximum value is about $0.00157 \mathrm{~K}^{-1}$ at $298 \mathrm{~K}$. Table 1 shows the values of the maximum sensitivities of $\mathrm{Tm}^{3+}$ in some different host matrices. By comparison, the value of the maximum sensitivity obtained in this work is close to that of $\mathrm{Tm}^{3+}$ in other systems, which suggests that a single microfiber has potential applications in the field of temperature sensing.

\section{Conclusion}

In summary, we have reported a straightforward synthesis of $\mathrm{Yb}^{3+} / \mathrm{Tm}^{3+}$ ion doped $\beta-\mathrm{NaYF}_{4}$ by a thermal decomposition method and subsequently nanocrystals co-doped with PMMA solution to obtain microfibers by employing a facile drawing method. The relationship between guide loss and propagation distance of different diameters of microfibers was measured and indicated that a single microfiber is typical of active waveguides. The upconversion emission spectra and sensitivity of a microfiber were obtained for a temperature range of $298 \mathrm{~K}$ to $338 \mathrm{~K}$. The maximum sensitivity was recorded as $0.00157 \mathrm{~K}^{-1}$ at $298 \mathrm{~K}$ which illustrates that the device can achieve higher sensitivity and it could easy be used for temperature sensing. 
The microfiber may excite the microsystem in flowing gas or fluid. Hence, this work will represent a new horizon for microlight emitting devices in photonic platforms.

\section{Conflicts of interest}

There are no conflicts to declare.

\section{Acknowledgements}

This work was funded by the National Natural Science Foundation of China (No. 61605031)and Postdoctoral Science Foundation of China (No. 2017T100226).

\section{Notes and references}

1 R. L. Leonard, A. R. Lubinsky and J. A. Johnson, J. Am. Ceram. Soc., 2017, 100, 1551-1560.

2 F. Liu, E. Ma, D. Q. Chen, Y. Yu and Y. S. Wang, J. Phys. Chem. B, 2006, 110, 20843-20846.

3 S. Jiang, P. Zeng, L. Q. Liao, S. F. Tian, H. Guo, Y. H. Chen, C. K. Duan and M. Yin, J. Alloys Compd., 2014, 617, 538-541. 4 A. K. Soni, R. Dey and V. K. Rai, RSC Adv., 2015, 5(44), 3499935009.

5 X. Xu, Z. Wang, P. Lei, Y. Yu, S. Yao, S. Song, X. Liu, Y. Su, L. Dong, J. Feng and H. Zhang, ACS Appl. Mater. Interfaces, 2015, 7(37), 20813-20819.

6 W. Xu, Q. Song, L. Zheng, Z. Zhang and W. Cao, Opt. Lett., 2014, 39(16), 4635-4638.

7 X. Wang, Q. Liu, P. Cai, J. Wang, L. Qin, T. Vu and H. J. Seo, Opt. Express, 2016, 24(16), 17792-17804.

8 S. Zhou, G. Jiang, X. Li, S. Jiang, X. Wei, Y. Chen, M. Yin and C. Duan, Opt. Lett., 2014, 39(23), 6687-6690.

9 R. Dey, A. Kumari, A. K. Soni and V. K. Rai, Sens. Actuators, B, 2015, 210, 581-588.

10 D. Chen, Z. Wang, Y. Zhou, P. Huang and Z. Ji, J. Alloys Compd., 2015, 646, 339-344.

11 X. Wang, Q. Liu, Y. Bu, C.-S. Liu, T. Liu and X. Yan, RSC Adv., 2015, 5(105), 86219-86236.

12 A. Pandey and V. K. Rai, Spectroscopic Techniques for Security Forensic and Environmental Applications, Nova Publisher, USA, 2014, pp. 279-292.

13 D. Jaque and F. Vetrone, Nanoscale, 2012, 4(15), 4301-4326.

14 M. Fujiwara, K. Toubaru, T. Noda, H. Q. Zhao and S. Takeuchi, Nano Lett., 2011, 11, 4362-4365.

15 S. C. Warren-Smith, S. Afshar and T. M. Monro, Opt. Express, 2010, 18, 9474-9485.

16 A. Leung, P. M. Shankar and R. Mutharasan, Sens. Actuators, $B, 2007,125,688-703$.

17 R. Yalla, F. Kien, M. Morinaga and K. Hakuta, Phys. Rev. Lett., 2012, 109, 063602.

18 A. Camposeo, Small, 2009, 5, 562.

19 X. Guo, Y. B. Ying and L. M. Tong, Acc. Chem. Res., 2014, 47, 656-666.

20 Z. L. Jiang, L. Y. Xin, L. H. Long, X. Wei and Z. Z. Guo, Acta Phys. Sin., 2013, 62, 240700-240706.
21 L. J. Zheng, X. Y. Gao, W. Xu and Z. G. Zhang, Chin. J. Lumin., 2012, 33, 944-948.

22 Z. Yong, P. Aidong, F. Hongbing, M. Ying and Y. Jiannian, Adv. Mater., 2008, 20, 1661-1665.

23 P. Wang, L. Zhang, Y. Xia, L. Tong, X. Xu and Y. Ying, Nano Lett., 2012, 12(6), 3145-3150.

24 H. Li, Y. Zhang, L. Shao, Z. Htwe and P. Yuan, Opt. Mater. Express, 2017, 7, 1077-1083.

25 Z. Q. Li and Y. Zhang, Nanotechnology, 2008, 19, 345606.

26 Y. S. Zhao, A. Peng, H. Fu, Y. Ma and J. Yao, Adv. Mater., 2008, 20(9), 1661-1665.

27 B. Yan, L. Liao, Y. M. You, X. J. Xu, Z. Zheng, Z. X. Shen, J. Ma, L. M. Tong and T. Yu, Adv. Mater., 2009, 21, 2436-2440.

28 R. Xia, G. Heliotis, Y. Hou and D. D. C. Bradley, Org. Electron., 2003, 4, 165-177.

29 D. Carroll, I. Lieberwirth and G. Redmond, Small, 2007, 7, 1178-1183.

30 R. Zhang, H. Yu and B. Li, Nanoscale, 2013, 4, 5856-5859.

31 H. Li, Y. Yang, H. Li, Y. Zhang and J. Yang, Sci. Rep., 2016, 6, 35941.

32 G. Morello, M. Moffa, S. Girardo, A. Camposeo and D. Pisignano, Adv. Funct. Mater., 2014, 24, 5225-5231.

33 G. Brambilla, V. Finazzi and D. J. Richardson, Opt. Express, 2004, 12, 2258-2263.

34 H. Yu and B. Li, Sci. Rep., 2013, 3, 1674.

35 R. J. Thrash and L. F. Johnson, J. Opt. Soc. Am. B, 1994, 11, 881.

36 G. Qin, W. Qin, C. Wu, S. Huang, D. Zhao, J. Zhang and S. Lu, Opt. Commun., 2004, 242, 215-219.

37 G. Qin, W. Qin, C. Wu, S. Huang, J. Zhang, S. Lv, D. Zhao and H. Liu, J. Appl. Phys., 2003, 93, 4328.

38 X. Wang, J. Zheng, Y. Xuan and X. Yan, Opt. Express, 2013, 21, 21596-21606.

39 S. A. Wade, S. F. Collins and G. W. Baxter, J. Appl. Phys., 2003, 94, 4743-4756.

40 K. Zheng, W. Song, G. He, Z. Yuan and W. Qin, Opt. Express, 2015, 23, 7653-7658.

41 T. V. Gavrilovic, D. J. Jovanovic, V. Lojpur and M. D. Dramicanin, Sci. Rep., 2014, 4, 4209.

$42 \mathrm{~W} . \mathrm{Xu}, \mathrm{X}$. Gao, L. Zheng, Z. Zhang and W. Cao, Sens. Actuators, B, 2012, 173, 250-253.

43 D. Jaque and F. Vetrone, Nanoscale, 2012, 4, 4301-4326.

44 Z. L. Jiang, L. Y. Xin, L. H. Long, X. Wei and Z. Z. Guo, Acta Phys. Sin., 2013, 62, 24070-240706.

45 W. Xu, X. Y. Gao, L. J. Zheng, Z. G. Zhang and W. W. Cao, Sens. Actuators, B, 2012, 173, 250-253.

46 L. J. Zheng, X. Y. Gao, W. Xu and Z. G. Zhang, Chin. J. Lumin., 2012, 33, 944-948.

47 A. F. Pereira, K. Upendra Kumar, W. F. Silva, W. Q. Santos, D. Jaque and C. Jacinto, Sens. Actuators, B, 2015, 213, 65-71.

48 L. Tong, X. Li, R. Hua, L. Cheng, J. Sun, J. Zhang, S. Xu, H. Zheng, Y. Zhang and B. Chen, Curr. Appl. Phys., 2017, 17, 999-1004.

49 N. N. Dong, M. Pedroni, F. Piccinelli, G. Conti, A. Sbarbati, J. E. RamírezHernández, L. M. Maestro, M. C. I. d. l. Cruz, F. Sanz-Rodriguez, A. Juarranz, F. Chen, F. Vetrone, J. A. Capobianco, J. G. Solé, M. Bettinelli, D. Jaque and A. Speghini, ACS Nano, 2011, 5, 8665-8671. 